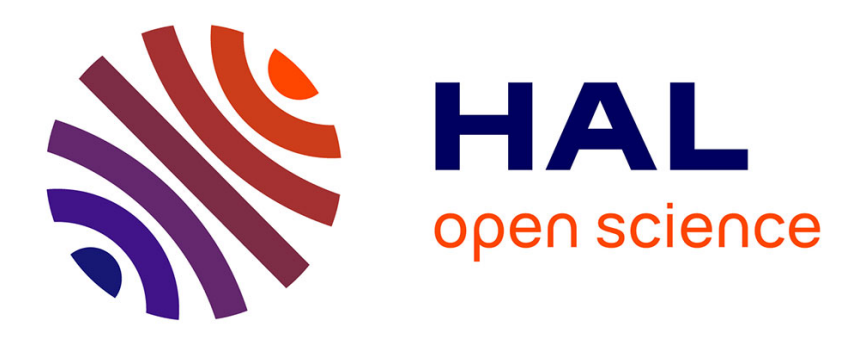

\title{
Comparison of three measurement methods of saturated hydraulic condutivity
}

\author{
C. Fallico, E. Migliari, S. Troisi
}

\section{To cite this version:}

C. Fallico, E. Migliari, S. Troisi. Comparison of three measurement methods of saturated hydraulic condutivity. Hydrology and Earth System Sciences Discussions, 2006, 3 (3), pp.987-1019. hal00298707

\section{HAL Id: hal-00298707 https://hal.science/hal-00298707}

Submitted on 14 Jun 2006

HAL is a multi-disciplinary open access archive for the deposit and dissemination of scientific research documents, whether they are published or not. The documents may come from teaching and research institutions in France or abroad, or from public or private research centers.
L'archive ouverte pluridisciplinaire HAL, est destinée au dépôt et à la diffusion de documents scientifiques de niveau recherche, publiés ou non, émanant des établissements d'enseignement et de recherche français ou étrangers, des laboratoires publics ou privés. 
Hydrol. Earth Syst. Sci. Discuss., 3, 987-1019, 2006 www.hydrol-earth-syst-sci-discuss.net/3/987/2006/

(C) Author(s) 2006. This work is licensed under a Creative Commons License.
Hydrology and Earth System Sciences Discussions

Papers published in Hydrology and Earth System Sciences Discussions are under open-access review for the journal Hydrology and Earth System Sciences

\section{Comparison of three measurement methods of saturated hydraulic condutivity}

C. Fallico, E. Migliari, and S. Troisi

Department of Soil Conservation of University of Calabria, Italy

Received: 6 April 2006 - Accepted: 12 April 2006 - Published: 14 June 2006

Correspondence to: C. Fallico (fallico@dds.unical.it)

\section{HESSD}

3, 987-1019, 2006

Measurement methods of saturated hydraulic condutivity

C. Fallico et al.

Title Page

Abstract

Introduction

Conclusions

References

Tables

Figures

14

I

4

Back

Close

Full Screen / Esc

Printer-friendly Version

Interactive Discussion 


\section{Abstract}

After pointing out the importance of the saturated hydraulic conductivity $\left(k_{s}\right)$ measurements and the difficulties and uncertainties that are present, and after recalling salient aspects of three well-known measurement methods of this parameter 5 (i.e. constant-head tension infiltrometer ( $\mathrm{TI})$ method, constant-head pressure infiltrometer (PI) method and soil core (SC) estimates method), the results of an investigation on data which were obtained during a measurement campaign on an area of $800 \mathrm{~m}^{2}$, on a sandy loam hillslope, located in Southern Italy, were carried out again here. Three sets of values of $k_{s}$, obtained with these measurement methods, were analyzed statis, verifying that the log-no one; moreover, the more significant statistical parameters of each set were compared (average value $\bar{k}$, amplitude $A$, coefficient of variation $C V$ and standard deviation $S D$ ), individualizing the more significant differences. The greatest value of hydraulic conductivity $\bar{k}_{s}$ was found with method (PI), while the smallest with (SC) and the intermediate with $(\mathrm{TI})$; these differences were translated into macroporosity and into the influence of the single measurement method.

Moreover, referring to the possible factors affecting the results, the importance can be noted of the structure, the texture and the soil events, in terms of utilization, which can affect the measure of $k_{s}$ leading often to very different values even for similar soils, but with a different history, independently of the coincidence of the measurement points and they can be determining to explain the differences affecting the results obtained in analogous investigations by other researchers.

Having confirmed that generalization is not possible, the need was emphasized to adopt the necessary devices relating to the specific measurement method, case by the limits of each situation.

Finally, the results of similar statistical analysis carried out on a greater number of $k_{s}$ values, measured through the $(\mathrm{TI})$ and $(\mathrm{PI})$ methods are shown in this paper, with

HESSD

3, 987-1019, 2006

Measurement methods of saturated hydraulic condutivity

C. Fallico et al.

Title Page

Abstract

Introduction

Conclusions

Tables

References

Figures

14

4

Back

Close

Full Screen / Esc

Printer-friendly Version

Interactive Discussion 
HESSD

\section{Introduction}

Water displacement capacity in the vadose zone is often characterized by the saturated hydraulic conductivity parameter $k_{s}$, which represents a basic property of the 5 soil in several contexts and practical problems of agronomy and engineering, such as in watering-system projects, in the study of contaminant transport, in remediation projects, to valuate the soil sorption and the capacity to make the water flow in the subsoil and to the aquifers and generally in water management problems.

Usually the $k_{s}$ parameter is directly measured in the field or laboratory; there are 10 several methods for $k_{s}$ measuring, but generally they provide differing and often incomparable values. The causes of this may be numerous, as will be better seen later, in part owing to the measurement technique (procedure of sample acquisition, extreme sensitivity to the given-soil volume dimension, flux geometry, etc.) and in part owing to the soil particularities (different physical and hydraulic characteristics, different struc15 ture, texture, etc.), as is well-known and documented in the literature (Reynolds et al., 2000; Lee et al., 1985; Clemente et al., 1994; White et al., 1992; Bagarello and Provenza, 1996).

In spite of the methods, comparison results are generally uncertain and linked to the specific measurement conditions. Investigating the causes, the motivations of these

differences and results obtained by different methods is interesting and an attempt is made to provide useful suggestions to choose the more suitable method for the given soil case by case.

To this purpose, in this work the results of an analysis on $k_{s}$ values are reported, obtained during a set of data acquisition, by means of three of the more usual measure25
3, 987-1019, 2006

Measurement methods of saturated hydraulic condutivity

C. Fallico et al.

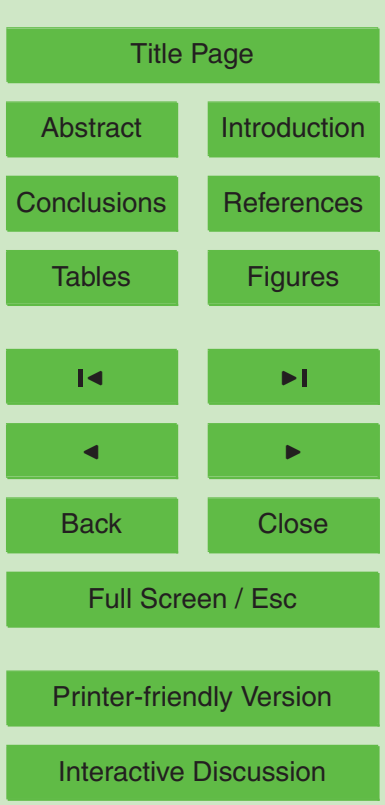

EGU 
antees rapidity and simplicity, or because it does not cause significant changes of the near saturation soils (Reynolds and Elrick, 1991; Ankeny et al., 1991; Perroux and White, 1988).

The apparatus of the measurement device and the relative procedure are also de5 scribed carefully in a lot of studies such as these above cited: it consists of a reservoirtower with a graduated scale on its wall. This reservoir is connected with a smaller tower, named "bubble tower", which acts as a Mariotte bottle and is used for fixing a negative head, in such a manner as to cause an infiltration velocity into the soil slightly less than that of water spilled freely on it.

10 Moreover, the reservoir is connected to a disc, which has a permeable membrane at the bottom through which the water goes out of the measurement device. It is advisable that the disc is not attached directly to the reservoir bottom, but connected to it by means of a gummed tube, in such a way as to avoid instability of the apparatus during the measurement, which otherwise might cause a movement of the same disc and a greater compactness of the soil, with consequent change of the macropores owing to the greater weight of the reservoir water column (Elrick and Reynolds, 1992).

Moreover, the disc does not touch the soil directly, but it is inter-situated on the contact layer, usually made of white silty sand, useful for a good hydraulic connection. This layer may sometimes cause flow impediment phenomena, especially in soils with high infiltration discharges; to avoid this impediment, the layer must have a non-excessive thickness and a hydraulic conductivity greater than that of the soil below. Also the elastic membrane on the base of the disc can affect the outgoing water flow from the measurement devices.

The classical theory forecasts the use of equations which provide the infiltration rate, 25 in steady state flow, one for each of the two or more constant heads taken in account for every measurement (Wooding, 1968; Logsdon and Jaynes, 1993; Angulo-Jaramillo et al., 2000). At this point it is necessary explain that for the same measurement the next heads, applied on the same connection layer, must prove in each case to be greater than the earlier ones, so as to avoid the entrance of air into the macropores;

HESSD

3, 987-1019, 2006

\section{Measurement methods of saturated hydraulic condutivity \\ C. Fallico et al.}

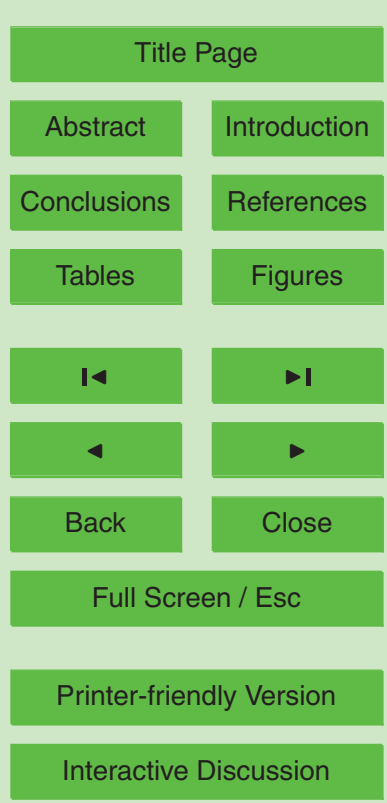

EGU 
this guarantees that all the initially active macropores continue to help the outflow, but does not exclude that other macropores act under the effect of greater heads (Elrick and Reynolds, 1992).

The $(\mathrm{PI})$ method is also much used for the measurements $k_{s}$ in the field; it is also 5 very simple and rapid, does not require contact with the sandy layer and is particularly suitable for the measurements in agricultural soil (Mertens et al., 2002).

The ring pressure infiltrometer consists of a tower used either as reservoir or as Mariotte bottle, for fixing the constant head to the measurements; this reservoir is connected to the base, by means of a small gum tube, to another tower, formed by 10 the transparent rigid tube, with a smaller dimension, where the water reaches the level correspondent to the fixed head. This tube is placed directly on the metallic ring, which is fixed into the soil and the infiltration water flows out through it (Reynolds, 1993a; Elrick and Reynolds, 1992; Angulo-Jaramillo et al., 2000).

The insertion of the ring may cause considerable disturbance to the state of the soil, 15 truncating the macropores intercepted by its walls, which end up no longer contributing to the flow; moreover, a preferential flow may create itself, as a short circuit, along the metallic walls of the ring, which changes the normal conditions of the water infiltration.

Also the sizes of the ring can affect the measurement, if they are relatively small, the considered soil portion prove to be reduced, the measure may prove scarcely representative of an assigned soil.

Also for the (PI) method the steady state flow during the constant-head measurement is considered; every measurement is repeated twice or more with constant heads increasing; it is necessary to consider that, nevertheless, in this case the pressure on the water infiltration is positive.

25 As in the previous method, for each constant head the equation which expresses the infiltration rate is written, so arriving at the determination of the $k_{s}$ parameter (Reynolds and Elrick, 1990; Angullo-Jaramillo et al., 2000).

The (SC) method is a laboratory method; the soil samples are analyzed with very simple techniques, after that they were saturated with immersion in water for some
HESSD

3, 987-1019, 2006

Measurement methods of saturated hydraulic condutivity

C. Fallico et al.

Title Page

Abstract

Introduction

Conclusions

Tables

References

Figures

14

$\rightarrow$

4

Back

Close

Full Screen / Esc

Printer-friendly Version

Interactive Discussion 
days (Klute and Dirksen, 1986; Hillel, 1980; Bouma, 1980; Reynolds, 1993b).

This $k_{s}$ measurement method is also among the more classical ones, the undisturbed samples are drawn out by inserting small metallic cylinders into the soil of a diameter and depth of generally about some centimetres $(5 \div 10 \mathrm{~cm})$, with a sharp bot-

5 tom edge for easy insertion into the soil. For its simplicity the (SC) method is used very frequently and often it is considered as a "sampler" method to calibrate or value other methods (Reynolds et al., 2000).

Nevertheless, it also has various limitation, such as those of PI method, like the disturbance caused to the soil sample during the inserting of the metallic ring, the 10 sizes of the sample and the possibility of short circuit along the walls of the metallic sampler or along the macropores which eventually cross all the samples.

\section{The field site}

To carry out the measurements only the one site was selected, located in Calabria (Southern Italy), in the basin of the Turbolo torrent, a tributary of the Crati river. The 15 site area presents a surface of $800 \mathrm{~m}^{2}(40 \mathrm{~m} \times 20 \mathrm{~m})$ and an average slope of about $6 \%$, on the longer side.

Geologically it is an area formed prevalently by sandy slimy conglomerate alluvial deposits; there is about $8.3 \mathrm{~m}$ depth from the trampling plane, a shallow aquifer, whose thickness is about $8 \mathrm{~m}$ and at the bottom there is a clay layer.

The upper soil in this area presents structural and textural characteristics typical of the agricultural soil with prevalent typology of sandy-loam. This field is cultivated annually with cereal cultivation (wheat, oats, purple medick) and was tilled with mechanic instruments immediately before the measurements; moreover, the grass was cut many times during the measurements and to disturb the soil as little as possible this cutting was done by hand.

Table 1 shows the principal physical characteristics of the above-mentioned soil, as mean values obtained from the structural and granulometric analysis of the upper-soil

\section{HESSD}

3, 987-1019, 2006

Measurement methods of saturated hydraulic condutivity

C. Fallico et al.

Title Page

Abstract

Introduction

Conclusions

Tables

References

Figures

14

-1

4

Back

Close

Full Screen / Esc

Printer-friendly Version

Interactive Discussion 
HESSD

\section{Materials and methods}

The measurement of $k_{s}$ for the (TI) method were performed by means of a single-disc infiltrometer, which consists of a measurement apparatus like that described earlier 5 and works at multiple heads. The disc diameter was $0.20 \mathrm{~m}$ and the basis-membrane had a pore diameter of about $53 \mu \mathrm{m}$; the contact layer was constituted of white sand with hydraulic conductivity of about $1 \times 10^{-4} \mathrm{~m} / \mathrm{s}$, while its thickness was kept constantly equal to about $1 \mathrm{~cm}$.

The support-surface of the sandy contact layer was adequately prepared before the measurement, removing the grass and proceeding next to levelling and brushing.

The contact layer diameter was always fixed slightly greater than that of the disc and often it was realized utilizing a metallic ring with a diameter of $0.25 \mathrm{~m}$.

The $k_{s}$ values, with the ( $\left.\mathrm{TI}\right)$ method, were determined considering, at least, two constant pressure head values, fixed in an increasing manner, and for each of them steady 15 state flow was achieved, continuing to measure the drawdowns of the water level reservoir and the relative time-ranges for at least another 5 min (Reynolds and Zebchuk, 1996); in every case the ranges were never less than 17 min for each constant head (Philip, 1986; Reynolds et al., 2000).

At the beginning, the reservoir was filled so as to avoid further additions of water 20 during the measurement, which could have generated air bubbles inside the instrument and the air trapped in the soil, for the redistribution of the water in it. (Elrick et al., 1989).

To determine $k_{s}$, the method of simultaneous equations (S.E.A.) was applied. It consists in writing a system with flux equations for each constant head, as indicated by Wooding (1968) and numerous other authors (Logsdon and Jaynes, 1993; Elrick and
3, 987-1019, 2006

Measurement methods of saturated hydraulic condutivity

C. Fallico et al.

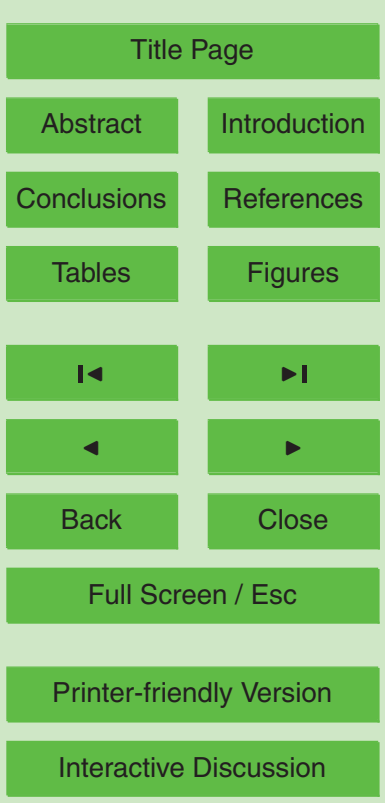

EGU 
thickness of $2.5 \mathrm{~mm}$ and a blunted lower rim for making insertion into the ground easy.

For this method each measurement was repeated twice with constant and timeincreasing pressure-heads, by acting in such a manner that the water initially present in the reservoir of the measurement device was sufficient to avoid intermediate fillings 5 until the end of the same measurement, which could have caused formation of the air bubbles in the small connection-tubes and in the soil. The time-range of the measurement for each of the constant heads was equal to $90 \mathrm{~min}$, so that the measurement in each location presented a range of at least $3 \mathrm{~h}$; so the attainment of steady state flow was guaranteed, which some authors consider sufficient, for the (PI) method, 10 a range max of 30 min for each value of the constant head (Reynolds et al., 2000). Also in this case the $k_{s}$ values were determined with the simultaneous equations approach (S.E.A.) as the modality described in the literature (Reynolds and Elrick, 1990; Reynolds, 1993a).

For the $k_{s}$ measurement by the (SC) method the soil core samples were removed 15 with a small $0.04 \mathrm{~m}$ diameter metallic cylinder with a height of $0.05 \mathrm{~m}$, and a sharp bottom rim to make ground penetration easy. The samples were all removed in the same location where the measurements had been executed by the $(\mathrm{PI})$ method; specifically, the sample was removed inside the metallic ring of the pressure infiltrometer, considering that the sizes of the latter were greater than those of the metallic cylinder used for the extraction of the samples. The work of sample extraction was effected at the end of the measure by the $(\mathrm{PI})$ method, paying maximum attention to disturb the soil as little as possible, removing at the beginning the material around the small metallic cylinder and successively detaching it from the bottom with the help of the metallic blade.

The $k_{s}$ values for each sample were obtained by using the classical procedure as 25 reported in the literature (Klute and Dirksen, 1986; Reynolds, 1993b); the analysis of these samples and the relative $k_{s}$ value determinations were carried out at the Laboratory of the Institute for Land and Water Management of the Katholieke Universiteit of Leuven (Belgium).

Moreover, it is necessary to specify the $k_{s}$ values, measured with the above-stated

\section{HESSD}

3, 987-1019, 2006

\section{Measurement methods of saturated hydraulic condutivity \\ C. Fallico et al.}

Title Page

Abstract

Introduction

Conclusions

Tables

References

Figures

14

$\rightarrow$

4

Back

Close

Printer-friendly Version

Interactive Discussion 
methods were all modified without considering the temperature changes, the effects of air trapping and other possible variations of the boundary conditions during the measurements.

During this data acquisition campaign further measurements of $k_{s}$ were performed, 5 limited to the $(\mathrm{TI})$ and $(\mathrm{PI})$ methods, also outside of the above-mentioned area, a larger total area equal to $2800 \mathrm{~m}^{2}(70 \mathrm{~m} \times 40 \mathrm{~m})$ was involved; the principal physical characteristics of the soil of this larger area remain equal to the ones relative to the area considered at the beginning and already shown.

\section{Statistical analysis}

10 At first, the probability distribution law which better describes the $k_{s}$ data sets corresponding to this three different methods was established.

As known, the characteristic parameters of the soil are generally described by a normal statistical frequency distribution or log-normal one (Warrick and Nielson, 1980).

In the present study the three sets of the $k_{s}$ values, obtained with the considered 15 methods, were analyzed by both the above-mentioned distribution laws; the results were successively compared, in terms of the determination coefficient $R^{2}$, determined by considering the linear regression of the reduced variable $u$ versus $k_{s}$, respectively, for the normal and log-normal distribution.

Successively, for each data set relative to the three methods, (TI) (PI) and (SC), the 20 values of the arithmetical average $(M)$, the geometrical one $\bar{k}_{s}$, the amplitude of the sets $(A)$, the coefficient of variation $(C V)$ and the standard deviation $(S D)$ were estimated, remembering that for the data described according to the log-normal distribution it is necessary to take into account the geometrical average and for the determination of this and the coefficient of variation the fitted relations must be used (Hastings and
Peacock, 1975). To make sure of correlation among the various methods, for each of the relative data sets, correlation with the other two was verified, estimating the Pearson correlation coefficient $(P)$.

\section{HESSD}

3, 987-1019, 2006

Measurement methods of saturated hydraulic condutivity

C. Fallico et al.

Title Page

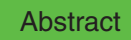

Introduction

Conclusions

Tables

References

Figures

14

$\rightarrow$

4

Back

Close

Full Screen / Esc

Printer-friendly Version

Interactive Discussion 
Moreover, test-F and the test-T were carried out, the former to verify the homogeneity of each data-set in terms of variance with the other two, the latter to verify if the sets of each pair could be considered belonging to two populations having the same average value; finally, the Student distribution furnished suggestions about the aver5 age value variation range, assuming an interval of confidence equal to $95 \%(5 \%$ level of significance ).

\section{Results}

Each of three sets of $23 k_{s}$ values obtained by the (TI), (PI) and (SC) methods, was statistically described by the normal and log-normal distribution; the results are shown 10 respectively in Fig. 1 and in Fig. 2. Moreover, in Table 2 the values of the determination coefficient $R^{2}$ are shown for each of the measurement methods.

This table, as well as Figs. 1 and 2, in which are shown respectively the representations on normal and log-normal fractil diagrams of these sets with the respective distribution, prove the log-normal distribution is the best fit. Consequently, assuming 15 such a distribution law for the description of the sets of $k_{s}$ values, the parameters $M$, $k_{s}, A, C V$ and $S D$ are estimated for each of these methods, as shown in Table 3.

The data set obtained by $(\mathrm{TI})$ method presents the value of $\bar{k}_{s}$ intermediate respecting the ones of the sets relative to the (PI) and (SC) methods; for the rest the amplitude $A$ is less, so also the values of the coefficient of variation $C V$ and standard deviation $S D$ are lower than the other two methods.

Regarding the $(\mathrm{PI})$ method, though it generates the data set with a $k_{s}$ value clearly bigger than the other two methods, while the $A, C V$ and $S D$ corresponding values are intermediate.

The (SC) method produces a data set with the $\bar{k}_{s}$ value lower than the other two 25 methods; on the contrary, the $A, C V$ and $S D$ parameters present the highest values.

Table 3 shows that $\bar{k}_{s}$ assumes different values for all three measurement methods; however, the values of this parameter for the (TI) and (SC) methods, although they

\section{HESSD}

3, 987-1019, 2006

Measurement methods of saturated hydraulic condutivity

C. Fallico et al.

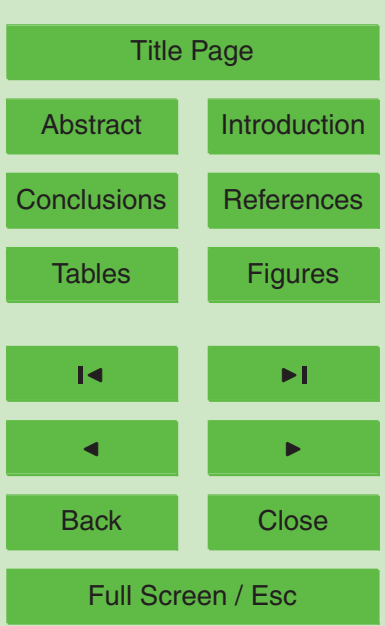

Printer-friendly Version

Interactive Discussion 
present one quantity order of difference, are sufficiently neighbouring and comparable, while the $(\mathrm{PI})$ one is greater by one order than that of $(\mathrm{TI})$ and by two orders than that of (SC).

However, the coefficient of variation $C V$ relative to the (SC) method is clearly greater 5 than that of (TI) and nearly four times larger than that of the (PI) method; so also the standard deviation $S D$ of the (SC) method is about two times that of the (PI) method and over six times greater than that of $(\mathrm{TI})$.

As already noticed, the greater amplitude belongs to the set of the (SC) method, while the smaller one is the ( $\mathrm{TI})$ method amplitude.

10 The Pearson-correlation coefficients values, determined among pairs of the data sets for verifying the existence of any correlation, are shown in Table 4; this verification was carried out both on normal values and on the logarithmic ones, considering for the latter the transformed variable In (Hastings and Peacock, 1975).

Test- $F$ and the test- $T$, carried out on the data sets of these methods, did not provide 15 the significant values, while the Student distribution, in an interval of confidence of $95 \%$, provided extreme values of the average shown in Table 5 for each method.

Referring to (TI) and (PI) measurements methods on the larger area of $2800 \mathrm{~m}^{2}$ mentioned earlier, it is necessary to underline that the relative sets of values of $k_{s}$, obtained by the respective methods, are certainly much more numerous than the ones treated till now; the values of $k_{s}$ relative to the (TI) method proved to be in all a good 126 while the $(\mathrm{PI})$-ones 45 , specifying that both the sets also include the values of the area of $800 \mathrm{~m}^{2}$, already examined.

Evidently no statistical comparison of the data sets could be carried out because the sets had different dimensions and consequently represented the respective populations which they can be thought to belong to in a different way.

However, also for the two further sets of $k_{s}$ values the representation as normal and log-normal distribution was carried out; in Table 6 the respective values of the coefficient of determination $R^{2}$ are shown; the latter values were calculated for each of the two measurement methods and for each of the distribution laws.
HESSD

3, 987-1019, 2006

Measurement methods of saturated hydraulic condutivity

C. Fallico et al.

Title Page

Abstract

Introduction

Conclusions

Tables

References

Figures

14

$\rightarrow 1$

4

Back

Close

Printer-friendly Version

Interactive Discussion

EGU 
Also in this case the greater representative nature of the data by the log-normal distribution is evident.

In Fig. 3 the representations of the two sets of $k_{s}$ values, also if limited to only the log-normal distribution, were shown again; in the figure, for both the methods, (TI) 5 and $(\mathrm{PI})$, also the distribution plots for the sets of smaller dimensions (23 values) were shown again so as to evidence the variations relative to each methods in spite of the exclusion of their comparison.

To be better able to perform the comparison between sets relative to the same measurement method, as shown again in Table 3, the values of the principal statistical 10 parameters of the wide sets are shown in Table 7, they are relative to the $(\mathrm{TI})$ and $(\mathrm{PI})$ methods.

\section{Discussion}

Describing the $k_{s}$ spatial variability, in many cases the large variability among the values of this parameter both in the context of the same method and in the comparison 15 of the different methods is not important, but rather being able to dispose of a greater number of measurements is determining; in other cases, however, the contrary happens and accuracy appears prevalent on the number (Lee et al., 1985).

On the other hand, focusing on this latter aspect, the differences of the $\bar{k}_{s}$ values comparable among several methods, by themselves do not provide reliable elements; so also it does not follow that the smaller value of $C V$ or $S D$ should lead to believing that the value of $\bar{k}_{s}$ be considered more accurate and therefore the corresponding method preferable.

It is, however, necessary and useful to analyze the possible causes which produced the differences of the values of the above-mentioned parameter utilizing different methods, taking in account the principal elements effecting the phenomenon.

In the examined case the statistical analysis, compared to what was proved by other researchers (Reynolds et al., 2000), underlined the presence of a significant correlation
HESSD

3, 987-1019, 2006

Measurement methods of saturated hydraulic condutivity

C. Fallico et al.

Title Page

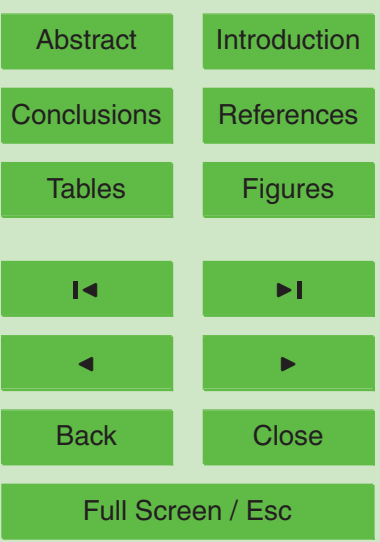

Printer-friendly Version

Interactive Discussion 
among the pairs of data relative to measurement methods, resulting in the Pearson correlation coefficient values shown in Table 4. However, the undoubtedly negative results of the statistical ( $\mathrm{F}$ and $\mathrm{T}$ ) tests show that these three different sets of values of $k_{s}$ must be thought of as belonging to three different populations, each of which 5 presents a clearly definite trend, different from others, as proves already evident from the Figs. 1 and 2. The diversity among the sources-populations of the $k_{s}$ value sets, relative to $(\mathrm{TI}),(\mathrm{PI})$ and $(\mathrm{SC})$ methods and, after all the different values of $\bar{k}_{s}$, must be attributed, as is known, also to the different techniques and modality of providing some water to the soil, to the different position assumed by macroporosity in each of them for 10 the following principal factors:

- characteristic sampling volume of each measurement method; in effect this volume in the (TI) method is owing to the disc diameter, in the $(\mathrm{PI})$ method to the ring diameter and in the (SC) method to the sampler diameter;

- flux geometry which is three-dimensional in the ( $\mathrm{TI}$ ) method, while it is prevalently mono-dimensional (vertical direction) in the (PI) and (SC) methods. If the distribution of the macropores induces flow directional anisotropy (horizontal/vertical), this circumstance can prove determining;

- soil disturbance, inexistent in the (TI) method, while in (PI) and (SC) methods it is owing to the ring insertion within the soil, which can truncate before hydraulically activate macropores, stopping or changing the water flow, as already noticed.

Referring to the examined case the average value of the hydraulic conductivity $\left(\bar{k}_{s}\right)$, relatively to the (TI) method, is comparable with the (SC) method one and by far lower than the $(\mathrm{PI})$ method . The disc dimensions of the $(\mathrm{TI})$ method $(20 \mathrm{~cm})$ appear, as already noticed, clearly greater than the ring of the $(\mathrm{PI})$ method $(9.8 \mathrm{~cm})$ and the sampler of the (SC) method $(4 \mathrm{~cm})$, and therefore, substantial differences of structure and texture apart, it is possible to suppose, relative to the (TI) method, an influence on the $\bar{k}_{s}$ value of the following possible causes:

HESSD

3, 987-1019, 2006

Measurement methods of saturated hydraulic condutivity

C. Fallico et al.

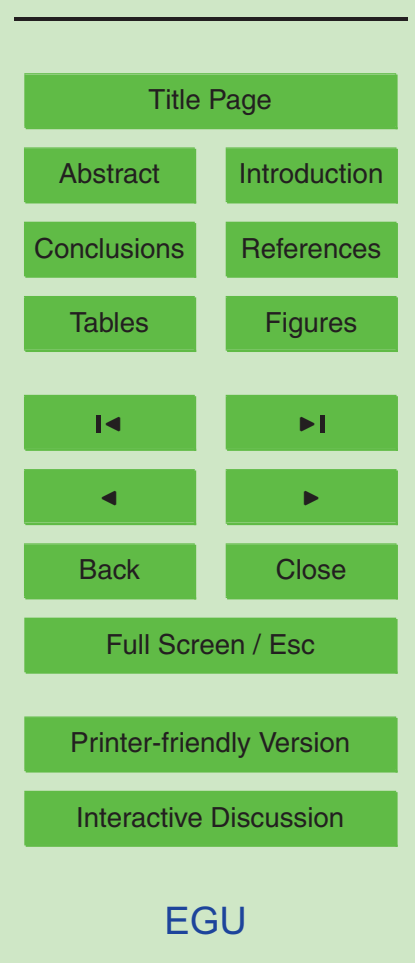


- the difficulty of the air passage in the Mariotte bottle of the disc infiltrometer or in the pipes-joint;

HESSD

- the impediment to the flow owing to the membrane;

- the impediment to the flow owing to the contact sandy layer;

- the influence of the algorithm;

- the three-dimensionality of the flux geometry.

However, the influence of the above-mentioned factors on the $\bar{k}_{s}$ value, relative to the (TI) method, most likely, might not have been noticeable, as asserted for the similar cases by other researchers (Reynolds et al., 2000); in fact, the measurements were carried out with the shrewdness necessary to limit these causes, as previously described. It is likely that other factors had greater weight, owing either to the macropores number present in the locations where the measurements were performed by this method and to the heterogeneity of the soil, or to possibility of their blocking during the procedure of preparation of the measurement surface which could occur, in spite of the great care taken; thus, the choice of the measurement locations could also affect the results, apart from the known subjectivity of the measurement operator.

The high value of $\bar{k}_{s}$, relative to the $(\mathrm{PI})$ method, as it has arisen in the present study, requires careful reflection. In effect the $(\mathrm{PI})$ method is not affected by a need to use membranes and contact layers and, at least in this case, it seems evident that any difficulties of air passage into the joint tubes and the Mariotte bottle can be excluded, which in this instrument acts also as reservoir.

It is likely that the $\bar{k}_{s}$ value of the (PI) method being greater than that of the two other methods is attributable to the soil disturbance during the ring insertion and to the presence of root channels and the presence of worm holes.

25 Specifically, the presence of roots could have a determining role, useful to furnish an explanation about the $\bar{k}_{s}$ value relative to the $(\mathrm{PI})$ method, higher than that of the
3, 987-1019, 2006

Measurement methods of saturated hydraulic condutivity

C. Fallico et al.

Title Page

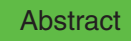

Introduction

Conclusions

Tables

References

Figures

14

$\rightarrow$

4

Back

Close

Full Screen / Esc

Printer-friendly Version

Interactive Discussion 
(TI) method, without excluding, however, possible infuences owing to the already cited factors, such as the membrane and contact layer.

In effect, although it is undeniable that the greater the intercepted-infiltration area, the greater is the number of macropores which potentially can be present in this area,

5 as also the influence of soil heterogeneity, in the case in examination this circumstance does not seem be confirmed; in fact, according to this reasoning, since the disc diameter is by far greater than the ring one, the $\bar{k}_{s}$ value relative to the (TI) method should have given a result greater than that of the $(\mathrm{PI})$ method, however the opposite situation is verified.

10 Most likely a reasonable explanation can be found through a careful analysis of the macroporosity influence induced on the soil topper by the grass roots, which, during the measurements, grew spontaneously and quickly on the soil, already soft from the recent working (Beven and Germann, 1982). To disturb the soil as little as possible, the grass was frequently extirpated by hand and with it also the roots; during this operation 15 it was verified that the roots had a length not greater than $10 \div 12 \mathrm{~cm}$ like tufts, often twined around one another.

Therefore, the correspondent macropores, presumably of the same length, were not able to affect the whole infiltration volume relative to the $(\mathrm{TI})$ method, identifiable with a bulb of about a diameter of $30 \div 40 \mathrm{~cm}$, while certainly they passed through the whole infiltration volume relative to the $(\mathrm{PI})$ method, determining a flow which, although it was substantially vertical in the zone near the surface of the soil, under the metallic walls of the ring, it finished by orienting prevalently in other directions, following the network of macropores produced by these roots.

Between the $\bar{k}_{s}$ value of the (PI) method and the (SC) method the present-survey difference proves to be much more surprising, because of the coincidence of the measurement locations, also because both the methods employ a metallic device in the soil and both of them present a prevalently vertical flow. The causes could reside in numerous factors; most likely the difference among the dimensions of the soil volumes which were involved in the two methods, (PI) and (SC), for the calculation of $k_{s}$, appeared

HESSD

3, 987-1019, 2006

Measurement methods of saturated hydraulic condutivity

C. Fallico et al.

Title Page

Abstract

Introduction

Conclusions

Tables

References

Figures

14

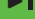

4

Back

Close

Printer-friendly Version

Interactive Discussion

EGU 
determining. In this case that is clear because of the difference between the ring and the sampler, but this circumstance was noticed by other researchers also when the two metallic devices, the ring and the sampler, presented the same dimensions (Reynold et al., 2000). In fact, in the (PI) method the infiltration flow produces a saturated soil 5 bulb immediately under the metallic ring, rounded by an unsaturated greater dimension soil zone, with an advancing wetting front; on the contrary, in the (SC) method the whole soil volume considered is only that of the metallic-cylinder soil sample (Elrick and Reynolds, 1992).

On the other hand, since in the (SC) method soil samples were taken out from the 10 inner-part of the ring infiltrometer of the (PI) method, a possible decreasing of the number of the intercepted macropores, because of the reduced dimensions of the sampler with respect to the ring, seems the logical consequence; moreover, these very reduced dimensions could have caused a soil disturbance amplification during insertion, with a consequent increasing of the occlusion influence of the intercepted macropores from metallic sampler walls on the water flow and its consequent drastic reduction.

Another significant cause of the difference between these two methods consists in the $(\mathrm{PI})$ method, where soil disturbance takes place only because of the ring insertion, while in that of the (SC) method it takes place because, as well as the insertion of the metallic sampler into the soil, also, and perhaps above all, during its extraction, which, in spite of care taken, can have a noticeable effect. A further difference between these two methods is because the (SC) method requires that the sample, before being analyzed in the laboratory, be saturated and maintained in this condition for a sufficiently long time. In fact, especially in the presence of clay, this can determine the partial or total closing of the splits and macropores, with consequent flow reduction; sometimes,

on the contrary, especially in structured soils, the splits and the macropores do not close themselves and often go on to extend themselves uninterruptedly from the top to the bottom of the sample.

In the examined case the soil samples were subjected to saturation for 4 days, before being analyzed in the laboratory. In this time-range the macropores can themselves be
HESSD

3, 987-1019, 2006

Measurement methods of saturated hydraulic condutivity

C. Fallico et al.

\section{Title Page}

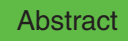

Introduction

Conclusions

Tables

References

Figures

14

$\rightarrow$

4

Back

Close

Printer-friendly Version

Interactive Discussion 
occluded because of swilling, given the small clay percentage, less than because of obstruction phenomena owing to the finer particles, or ceding and collapsing of the walls of the macropores and eventual splits, probably owing to the sometimes excessively friable soil state, caused by its evolution, prior to the measurement campaign; 5 in fact, this circumstance can be determining in such a semi-structural soil and can exclude every influence of the grass root channels and macropores network which, on the other hand, is assigned a determining function in the $(\mathrm{PI})$ method.

It cannot be excluded, in spite of such a long saturation period, that sufficient air remained entrapped in the soil samples to stop the water flow through the macropores.

10 As already said, to survey the spatial distribution of $k_{s}$ the number of measurements is of fundamental importance. In fact, in this case one needs to take into account that when the dimensions of the data sets increase, also the correspondent values of the characteristic parameters $M, \bar{k}_{S}, A, C V$ and $S D$ change, the larger is the number $\mathrm{n}$ of the set values the more it represents the source-population.

15 Regarding this case, comparing separately the (TI) method and the (PI) method parameter values of Table 3, obtained by two data sets both constituted of 23 values, with the correspondent ones of Table 7 , relative to data sets constituted respectively of 126 and 45 values, it is possible to see that, also if the data number increases, very noticeably for the sets of the (TI) method, caused a variation of the above-mentioned ${ }_{20}$ parameter values, the ones relative to $\bar{k}_{s}$, are not changed significantly, maintaining unchanged the respective order of quantity; the same thing is observed about the arithmetic-average value. Significant changes are obtained, on the contrary, in the amplitude $A$, coefficient of variation $C V$ and standard deviation $S D$, as, on the other hand, this was expected.

Here it was not possible to effect any comparison between the two different data sets obtained either by the (TI) method or the (PI) method, because of their different dimensions. However, examining separately the pairs of the data sets correspondent to the same method, a trend variation can be seen for each of the relative belongingpopulations, as shown in Fig. 3. This variation proves to be significant only for the (TI)
HESSD

3, 987-1019, 2006

\section{Measurement methods of saturated hydraulic condutivity \\ C. Fallico et al.}

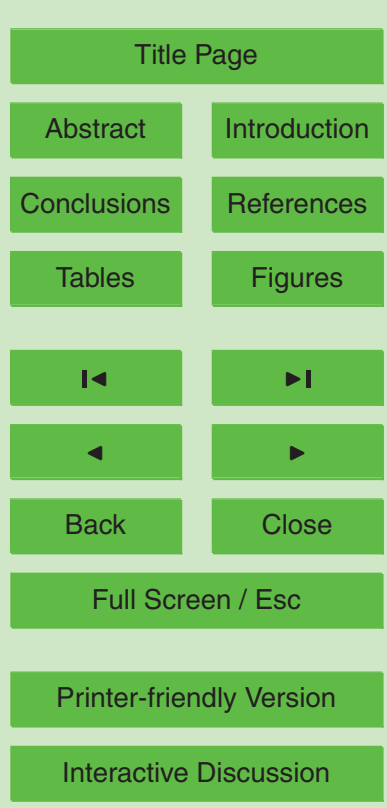

EGU 


\section{HESSD}

\section{Conclusions}

This study, on the comparison of $k_{s}$ measurement methods, revealed numerous uncertainties owing to the absence of a reference technique and benchmarks; moreover, the extreme difficulty should be noticed, perhaps the impossibility, of obtaining some directions of general validity, because of the great variability of the measurement conditions. This is linked either to the different types of soil, or to the different methods and measurement devices utilized.

Thus, according to other researchers (Lee et al., 1985; Reynolds et al., 2000), it is retrained opportune evidence the usefulness of these studies, because they provide information about the devices to adopt during the measurements, on possible inconveniences and, in the last analysis, on the choice of the measurement method.

On the agricultural soil of the "Turbolo" basin, examined in the present work, several measurements of the saturated hydraulic conductivity $k_{s}$, were carried out, by using 15 the ( $\mathrm{Tl}),(\mathrm{Pl})$ and $(\mathrm{SC})$ methods, analyzing the obtained results statistically and comparing the more significant statistical parameters of the correspondent data sets, which presented a good degree of correlation.

However, the statistical tests evidenced the clear belonging of three sets of $k_{s}$ values to different populations. The maximum amplitude $A$ of the set was the one relative to the (SC) method, as were the coefficient of variation (CV) and standard deviation SD. Referring to the value of $\bar{k}_{s}$, the maximum was the one of the set relative to the (PI) method, while the values of the two other methods (TI) and (SC) were noticeably comparable. The causes of such a difference, even though not evident, can be researched in the following points:

- difference between the reference volumes of each methods;

- different flux geometries;
3, 987-1019, 2006

Measurement methods of saturated hydraulic condutivity

C. Fallico et al.

Title Page

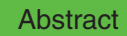

Introduction

Conclusions

Tables

References

Figures

14

4

Back

Close

Full Screen / Esc

Printer-friendly Version

Interactive Discussion 
- different procedures of water application inside the soil;

- different boundary conditions;

HESSD

- soil heterogeneity.

Regarding the ( $\mathrm{TI})$ method, it seems that the $\bar{k}_{s}$ value can be considered mainly af5 fected by the specific characteristics of the macropores in the measurement soil, then by the local soil heterogeneities, soil preparation procedures and, perhaps to a lesser degree, by other causes outlined earlier.

Relating to the (PI) method, as well as to the soil heterogeneity, a noticeable influence can be assigned to the disturbance of the ring insertion into the soil and to the 10 presence of roots, that, very likely, may have influenced the macroporosity, in a determining manner and with the modality as shown above, and, in a less probable way, to the remaining reasons listed above. The $\bar{k}_{s}$ values obtained by the (SC) method, lower than for the two other methods, very probably are caused by the soil sample disturbance owing to the extraction and eventual macroporosity variations occurring during 15 the saturation and, above all, to the limited sampler dimensions and, therefore, to the corresponding intercepted area, without, however, excluding the possible influence of other above-cited factors.

Therefore, it is rational to believe that, in this case, the (PI) method over-estimated the $\bar{k}_{s}$ value, while the (TI) and (SC) methods under-estimated this parameter.

20 In other words it can be considered that the $(\mathrm{PI})$ and $(\mathrm{SI})$ methods provide a $\bar{k}_{s}$ value, more representative of the soil layer nearer to the surface (about $10 \div 15 \mathrm{~cm}$ ), the first tending to give over-estimated values of this parameter and the second underestimated values: while the $(\mathrm{TI})$ method provides a representative value of the larger soil volume about $30 \div 40 \mathrm{~cm}$ of depth, with a probable under-estimation of $\bar{k}_{s}$ for abovestated the reason.

On the basis of this behaviour, in each case the different function of the macroporosity in the three methods, $(\mathrm{TI}),(\mathrm{PI})$ and $(\mathrm{SC})$, remains and the foregoing is intended

Measurement methods of saturated hydraulic condutivity

C. Fallico et al.

Title Page

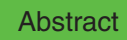

Introduction

Conclusions

Tables

References

Figures

14

I

4

Back

Close

Full Screen / Esc

Printer-friendly Version

Interactive Discussion 
to furnish suggestions about the modality affecting the $k_{s}$ measurements in each of considered methods (Bouma, 1982; Beven and Germann, 1982).

The choice of the method to adopt is certainly not simple, because it is not possible to assume that the measurements carried out by means one of them is more 5 reliable than the ones effected by means of the others; however, it is certainly possible to underline the usefulness of taking into account the circumstances emerging in the context of the present investigation and the opportunity to estimate carefully, case by case, the inconveniences which one meets using each of the considered methods and the possible remedies.

10 In any case it is necessary to point out that, as expected, the results obtained by means of a comparison of the three methods considered in this work do not always prove to be coincident with those obtained by other researchers, who effected similar investigations on soil of the same type (Reynolds et al., 2000; Lee et al., 1985). These differences, expected, because of the difficulty already referred to, of generalizing the results, very probably, can be associated with the specific conditions of the texture and structure of the different soils, which confirms the determining influence that such characteristics can have on the values of the investigated parameters, such as the hydraulic conductivity $\bar{k}_{s}$ (Bouma, 1983).

From the present investigation it seems, however, clear that the difference among $\bar{k}_{s}$ values, measured through different methods, depends prevalently on the particularities of the individual methods and certainly to a lesser extent, on the choice of the measurement location, just as it emerges from the diversity of the $\bar{k}_{s}$ values obtained by the $(\mathrm{PI})$ and $(\mathrm{SC})$ methods, whose measurements were carried out at the same location, and, instead, on the relative proximity among the values of this parameter for the $25 \mathrm{(TI})$ and (SC) methods, whose measurements were carried out at completely different locations.

Regarding the influence that the number of measurements can have on the results of investigations of this type, from the present study, limited to the ( $\mathrm{TI})$ and $(\mathrm{PI})$ methods, only an improvement of the statistical significance of the single data sets emerges,

HESSD

3, 987-1019, 2006

Measurement methods of saturated hydraulic condutivity

C. Fallico et al.

Title Page

Abstract

Introduction

Conclusions

Tables

References

Figures

14

$\rightarrow 1$

4

Back

Close

Full Screen / Esc

Printer-friendly Version

Interactive Discussion 
while the values of the respective investigated parameters have not undergone substantial changes.

However, it is necessary to specify that here only the strictly statistical influence was considered, without taking into account the possible influence of an increase in 5 the investigation area, despite verifying the permanence of the same typology and the same soil characteristics, because the present study did not in any way intend to consider aspects relative to the spatial variability of hydraulic conductivity.

It can be confirmed that the choice of the method for the measurement of saturated hydraulic conductivity $\bar{k}_{s}$ is certainly not simple, but careful valuation of the advantages 10 and the limits of each of the three considered methodologies can help to individuate the most suitable and convenient method to solve the specific problem under examination.

Acknowledgements. The authors thank J. Feyen, Director of the Institute for Land and Water Management of the Katholieke Universiteit Leuven (Belgium), for his precious suggestions and to have allowed this research, furnishing the measurement devices and performing the labo15 ratory tests; furthermore they thank, also, J. Mertens, Researcher of the same institute, who participated in the initial stage of the research.

\section{References}

Angulo-Jaramillo, R., Vandervaere, J. P., Roulier, S., Thony, J. L., Gaudet, J. P., and Vauclin, M.: Field measurement of soil surface hydraulic properties by disc and ring infiltrometers. A review and recent developments, Soil \& Tillage Research, 55, 1-29, 2000.

Ankeny, M. D., Ahmed, M., Kaspar, T. C., and Horton, R.: Simple field method for determining unsaturated hydraulic conductivity, Soil Sci. Soc. Am. J., 55, 467-470, 1991.

Bagarello, V. and Provenza, G.: Factors affecting field and laboratory measurements of saturated hydraulic conductivity, Trans. ASHE, 39, 153-159, 1996.

Beven, K. and Germann, P.: Macropores and water flow in Soils, Water Resour. Res., 18, 5, 1311-1325, 1982.

Bouma, J.: Field measurement of soil hydraulic properties characterizing water movement through swelling clay soils, J. Hydrol., 45, 149-158, 1980.

\section{HESSD}

3, 987-1019, 2006

Measurement methods of saturated hydraulic condutivity

C. Fallico et al.

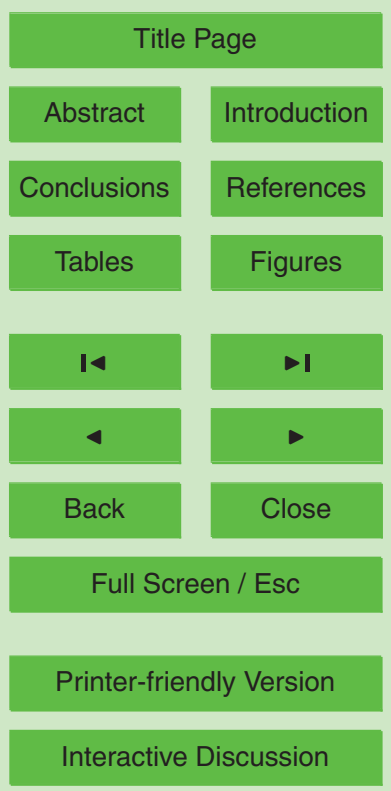

EGU 
Bouma, J.: Measuring the hydraulic conductivity of soil horizons with continuous macropores, Soil Sci. Soc. Am. J., 46, 438-441, 1982.

Bouma, J.: Use of soil survey data to select measurement techniques for hydraulic conductivity, Agric. Water Manage, 6, 177-190, 1983.

5 Clemente, R. S., De Jong, R., Hayhoe, H. N., Reynolds, W. D., and Hares, M.: Testing and comparison of three unsaturated soil water flow models, Agric. Water Manage, 25, 135-152, 1994.

Elrick, D. E., Reynolds, W. D., and Tan, K. A.: Hydraulic conductivity measurements in the unsaturated zone using improved well analysis, Graundwater Monit. Rev., 9, 184-193, 1989.

Elrick, D. E. and Reynolds, W. D.: Infiltration from constant-head well permeameters and infiltrometers, in: Advances in measurement of soil physical properties: Bringing theory into practice, edited by: Topp, G. C., Reynolds, W. D., and Green, R. E., SSSA Spec. Publ., 30, Madison, WI, 1-24, 1992.

Elrick, D. E., Parkin, G. W., Reynolds, W. D., and Fallow, D. J.: Analysis of early-time and 15 steady-state single-ring infiltration under falling head conditions, Water Resour. Res., 31, 1883-1893, 1995.

Hastings, N. A. J. and Peacock, J. B.: Statistical distributions, Halsted Press, New York, 1975.

Herman, S., Mertens, J., Timmerman, A., and Feyen, J.: Comparison of tension infiltrometer, single-ring pressure infiltrometer and soil core $\mathrm{K}_{\text {sat }}$ estimates on a sandy loam hillslope, Proceedings of EGS-AGU-EUG Joint Assembly, Nice (France), 2003.

Hillel, D.: Applications of soil physics. Academic Press, New York, USA, 1980.

Klute, A. and Dirksen, C.: Hydraulic conductivity and diffusivity: Laboratory methods, in: Methods of soil analysis, edited by: Klute, A., Part. 1. 2nd. Ed. Agron. Monogr. 9, ASA and SSSA, Madison, WI, 687-734, 1986.

Lee, D. M., Reynolds, W. D., Eldrick, D. E., and Clothier, B. E.: A Comparison of Three Field Methods for Measuring Saturated Hydraulic Conductivity, Can. J. Soil Sci., 65, 563-573, 1985.

Logsdon, S. D. and Jaynes, D. B.: Methodology for determining hydraulic conductivity with tension infiltrometers, Soil Sci. Soc. Am. J., 57, 1426-1431, 1993.

30 Mertens, J., Jacques, D., Vanderborght, J., and Feyen, J.: Characterisation of the fieldsaturated hydraulic conductivity on a hillslope: In situ single ring pressure infiltrometer measurements, J. Hydrol., 263, 217-229, 2002.

Perroux, K. M. and White, I.: Designs for disc permeameters, Soil Sci. Soc. Am. J., 52, 1205-

HESSD

3, 987-1019, 2006

Measurement

methods of saturated hydraulic condutivity

C. Fallico et al.

Title Page

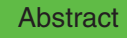

Introduction

Conclusions

Tables

References

Figures

14

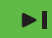

4

Back

Close

Full Screen / Esc

Printer-friendly Version

Interactive Discussion 
$1215,1988$.

Philip, J. R.: Linearized unsteady multidimensional infiltration, Water Resour. Res., 22, 17171727, 1986.

Reynolds, W. D.: Saturated hydraulic conductivity: Field measurement, in: Soil Sampling and 5 methods of analysis, edited by: Carter, M. R., Can. Soc. Soil Sci., Lewis Publ., Boca Raton, FL, 599-613, 1993a.

Reynolds, W. D.: Saturated hydraulic conductivity: Laboratory measurement, in: Soil Sampling and methods of analysis, edited by: Carter, M. R., Can. Soc. Soil Sci., Lewis Publ., Boca Raton, FL, 589-598, 1993b.

10 Reynolds, W. D. and Elrick, D. E.: Ponded infiltration from a single ring. Part. 1. Analysis of steady flow, Soil Sci. Soc. Am. J., 54, 1233-1241, 1990.

Reynolds, W. D. and Elrick, D. E.: Determination of hydraulic conductivity using a tension infiltrometer, Soil Sci. Soc. Am. J., 55, 633-639, 1991.

Reynolds, W. D. and Zebchuk, W. D.: Use of contact material in tension infiltrometer measurements, Soil Tech., 9, 141-159, 1996.

Reynolds, W. D., Bowman, B. T., Brune, R. R., Drury, C. F., and Tan., C. S.: Comparison of Tension Infiltrometer, Pressure Infiltrometer and Soil Core Estimates of Saturated Hydraulic Conductivity, Soil Sci. Soc. Am. J., 64, 478-484, 2000.

Warrick, A. W. and Nielsen, D. R.: Spatial variability for soil physical properties in the field, in: Applications of soil physics, Hillel, D., Academic Press, Toronto, 319-344, 1980.

White, I., Sully, M. J., and Perroux, K. M.: Measurement of surface-soil hydraulic properties: Disk permeameters, Tension infiltrometers and other techniques, in: Advances in measurement of soil physical properties: Bringing theory into practice, edited by: Topp, G. C., Reynolds, W. D., and Green, R. E., SSSA Spec. Publ. 30, SSSA, Madison, WI, 69-103, 1992.

Wooding, R. A.: Steady infiltration from a shallow circular pond, Water Res., 4, 1259-1273, 1968.

\section{HESSD}

3, 987-1019, 2006

Measurement

methods of saturated hydraulic condutivity

C. Fallico et al.

Title Page

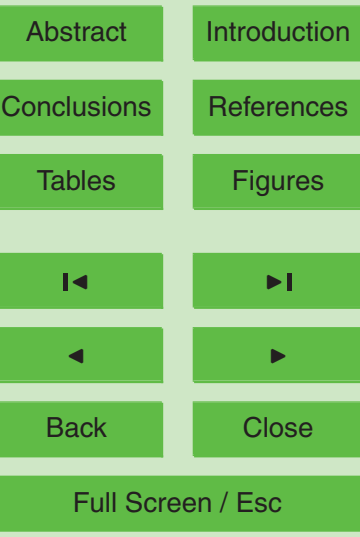

Printer-friendly Version

Interactive Discussion 


\section{HESSD}

3, 987-1019, 2006

\section{Measurement methods of saturated hydraulic condutivity}

C. Fallico et al.

Table 1. Soil physical characteristics.

\begin{tabular}{cccccc}
\hline $\begin{array}{c}\text { \% of the soil } \\
\text { samples }\end{array}$ & $\begin{array}{c}\text { soil type } \\
\text { (USDA classification) }\end{array}$ & \multicolumn{3}{c}{$\begin{array}{c}\text { Soil texture in top } \\
\text { mean values (early } 10 \mathrm{~cm})\end{array}$} & $\begin{array}{l}\text { Soil structure in top } \\
(\text { early } 10 \mathrm{~cm})\end{array}$ \\
\hline 70 & Sand \% loam & 60 & 26 & 14 & Clay \% \\
\hline 30 & loam & 41 & 37 & 22 & $\begin{array}{l}\text { single grain, friable, with } \\
\text { high presence of bio- } \\
\text { pores, roots and aggre- } \\
\text { gates }\end{array}$ \\
\hline
\end{tabular}

Title Page

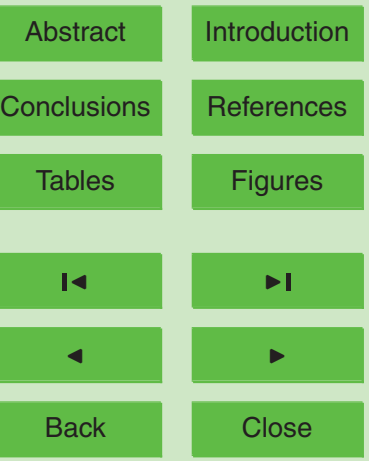

Full Screen / Esc

Printer-friendly Version

Interactive Discussion 


\section{HESSD}

3, 987-1019, 2006

Measurement methods of saturated hydraulic condutivity

C. Fallico et al.

Table 2. Goodness of fit of cumulative normal and lognormal $k_{s}$ distributions as described by the coefficient of determination $\mathrm{R}^{2}$.

\begin{tabular}{ccc}
\hline $\begin{array}{c}\text { Measurement } \\
\text { method }\end{array}$ & $\begin{array}{c}\text { Values of } \mathrm{R}^{2} \text { for the } \\
\text { normal distribution }\end{array}$ & $\begin{array}{c}\text { Values of } \mathrm{R}^{2} \text { for the } \\
\text { log-normally } \\
\text { distribution }\end{array}$ \\
\hline $\mathrm{TI}$ & 0.875 & 0.0929 \\
$\mathrm{PI}$ & 0.858 & 0.937 \\
$\mathrm{SC}$ & 0.515 & 0.961 \\
\hline
\end{tabular}

Title Page

Abstract

Introduction

Conclusions

References

Tables

Figures

14

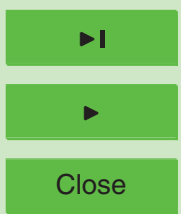

Back 


\section{HESSD}

3, 987-1019, 2006

Measurement methods of saturated hydraulic condutivity

C. Fallico et al.

Table 3. Mean values ( $\mathrm{M}$ and $\left.\bar{k}_{s}\right)$, range $\left(\mathrm{A}=k_{s} \max -k_{s} \min \right)$, coefficient of variation (CV) and standard deviation (SD) for the sets of $23 k_{s}$ values relative to each of considered methods.

\begin{tabular}{cccccc}
\hline $\begin{array}{c}\text { Measurement } \\
\text { method }\end{array}$ & $\mathrm{M}(\mathrm{m} / \mathrm{s})$ & $\bar{k}_{\mathrm{s}} \times 10^{-5}(\mathrm{~m} / \mathrm{s})$ & $\mathrm{A}$ (Range) & $\mathrm{CV}(\%)$ & $\mathrm{SD}$ \\
\hline $\mathrm{TI}$ & -10.97 & 1.72 & 0.70 & 19.93 & 1.22 \\
$\mathrm{PI}$ & -10.03 & 33.91 & 6.28 & 207.74 & 5.07 \\
$\mathrm{SC}$ & -11.99 & 0.62 & 7.09 & 786.24 & 7.65 \\
\hline
\end{tabular}

Title Page

Abstract

Introduction

Conclusions

References

Tables

Figures

14

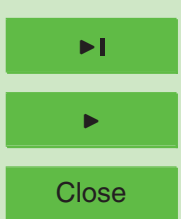

Back

Close

Full Screen / Esc

Printer-friendly Version

Interactive Discussion 


\section{HESSD}

3, 987-1019, 2006

Measurement methods of saturated hydraulic condutivity

C. Fallico et al.

Table 4. Pearson correlation coefficients $(\mathrm{P})$ of $(\mathrm{TI}),(\mathrm{PI})$ and $(\mathrm{SC})$ methods, for normal value and for In-transformed.

\begin{tabular}{ccc}
\hline Measurement method & \multicolumn{2}{c}{$\mathrm{P}$} \\
\hline & normal series & In-transformed series \\
\hline TI vs. PI & 0.952 & 0.920 \\
TI vs. SC & 0.883 & 0.972 \\
PI vs. SC & 0.896 & 0.974 \\
\hline
\end{tabular}

Title Page

Abstract

Introduction

Conclusions

References

Tables

Figures

14

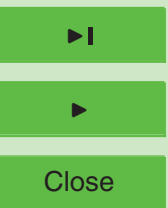

Back

Full Screen / Esc

Printer-friendly Version

Interactive Discussion 


\section{HESSD}

3, 987-1019, 2006

Measurement methods of saturated hydraulic condutivity

C. Fallico et al.

Table 5. Variation ranges of the average value $\bar{k}_{s}$ estimated by the Student distribution, for the interval of confidence of $95 \%$.

\begin{tabular}{|c|c|c|}
\hline \multirow[t]{2}{*}{ Measurement method } & \multicolumn{2}{|c|}{ Range of $\bar{k}_{s}$} \\
\hline & normal values ${ }^{-6}(\mathrm{~m} / \mathrm{s})$ & In-transformed values \\
\hline $\mathrm{TI}$ & $16225 \div 19678$ & $-11042 \div-10860$ \\
\hline $\mathrm{PI}$ & $362634 \div 863519$ & $-10730 \div-9338$ \\
\hline SC & $6475 \div 51980$ & $-12865 \div-11120$ \\
\hline
\end{tabular}

Title Page

Abstract

Introduction

Conclusions

References

Tables

Figures

14

4

Back

Close

Full Screen / Esc

Printer-friendly Version

Interactive Discussion 


\section{HESSD}

3, 987-1019, 2006

\section{Measurement} methods of saturated hydraulic condutivity

C. Fallico et al.

Table 6. Goodness of fit of cumulative normal and lognormal $k_{s}$ distributions as described by the coefficient of determination $\mathrm{R}^{2}$, for the sets of $k_{s}$ values relative to $(\mathrm{TI})$ and $(\mathrm{PI})$ methods and an area of $2800 \mathrm{~m}^{2}$.

\begin{tabular}{ccc}
\hline Measurement method & $\begin{array}{c}\text { Values of } R^{2} \text { for the normal } \\
\text { distribution }\end{array}$ & $\begin{array}{c}\text { Values of } R^{2} \text { for the log-normal } \\
\text { distribution }\end{array}$ \\
\hline$(\mathrm{TI})_{\text {Tot }}$ & 0.670 & 0.857 \\
$(\mathrm{PI})_{\text {Tot }}$ & 0.753 & 0.946 \\
\hline
\end{tabular}

Title Page

Abstract Introduction

Conclusions References

Tables Figures 14

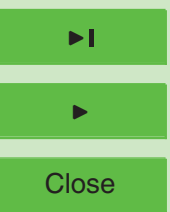

Back 


\section{HESSD}

3, 987-1019, 2006

Measurement methods of saturated hydraulic condutivity

C. Fallico et al.

Table 7. Mean values of the main statistical parameters for the wide sets of $k_{s}$ values, relative to $(\mathrm{TI})$ and $(\mathrm{PI})$ methods.

\begin{tabular}{ccccccc}
\hline Measurement method & $\mathrm{n}$ & $\mathrm{M}$ & $\bar{k}_{s} \times 10^{-5}(\mathrm{~m} / \mathrm{s})$ & $\mathrm{A}($ Range $)$ & $\mathrm{CV}$ & $\mathrm{SD}$ \\
\hline $\mathrm{TI}$ & 126 & -10.93 & 1.79 & 4.51 & 78.73 & 2.00 \\
$\mathrm{PI}$ & 45 & -7.67 & 46.74 & 5.66 & 209.43 & 3.66 \\
\hline
\end{tabular}




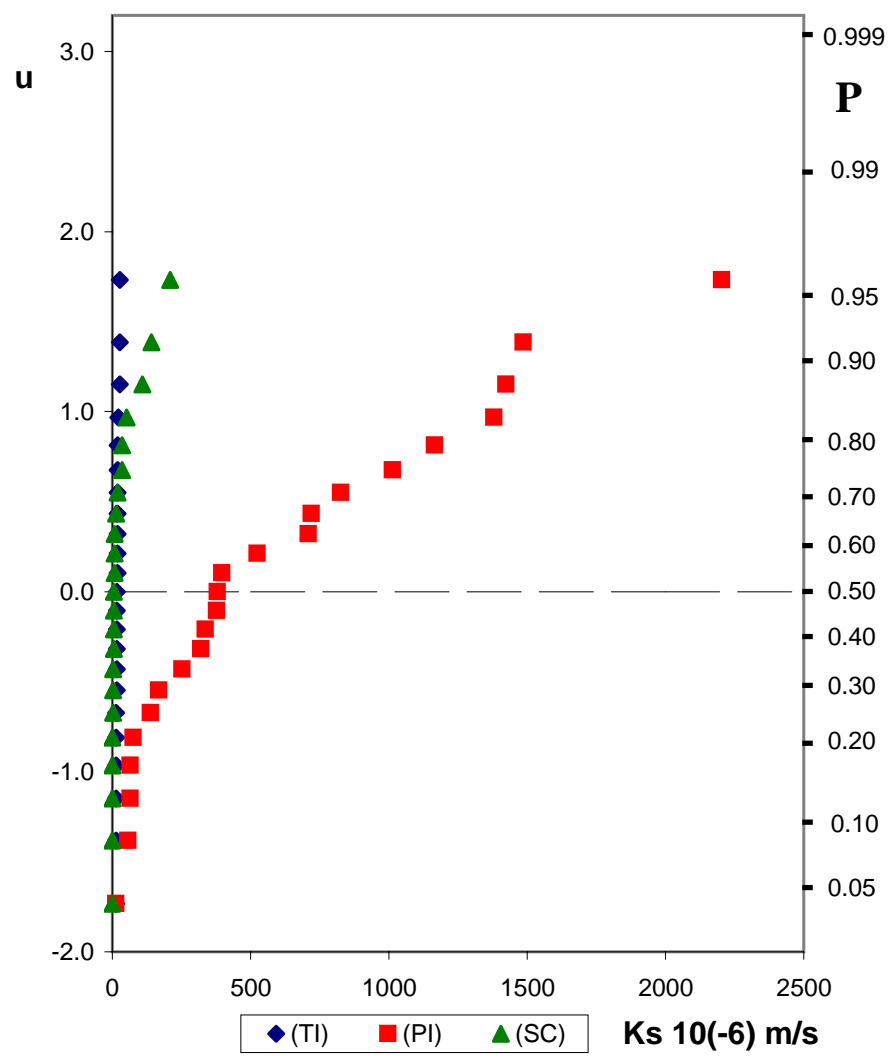

3, 987-1019, 2006

Measurement
methods of saturated
hydraulic condutivity

C. Fallico et al.

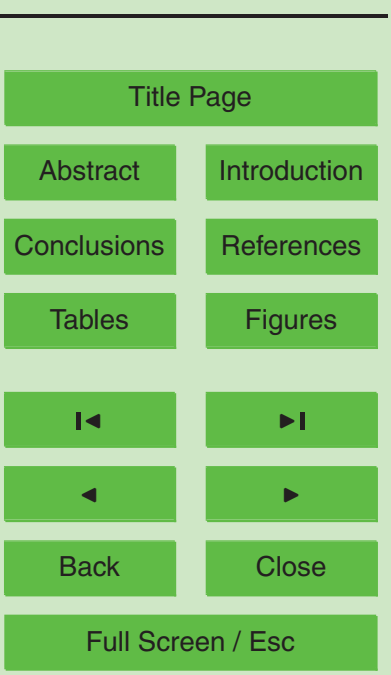

Printer-friendly Version

Fig. 1. Fractil diagram of the $k_{s}$ values by the normal distribution, for the (TI), $(\mathrm{PI})$ and $(\mathrm{SC})$ measurement methods.

Interactive Discussion 


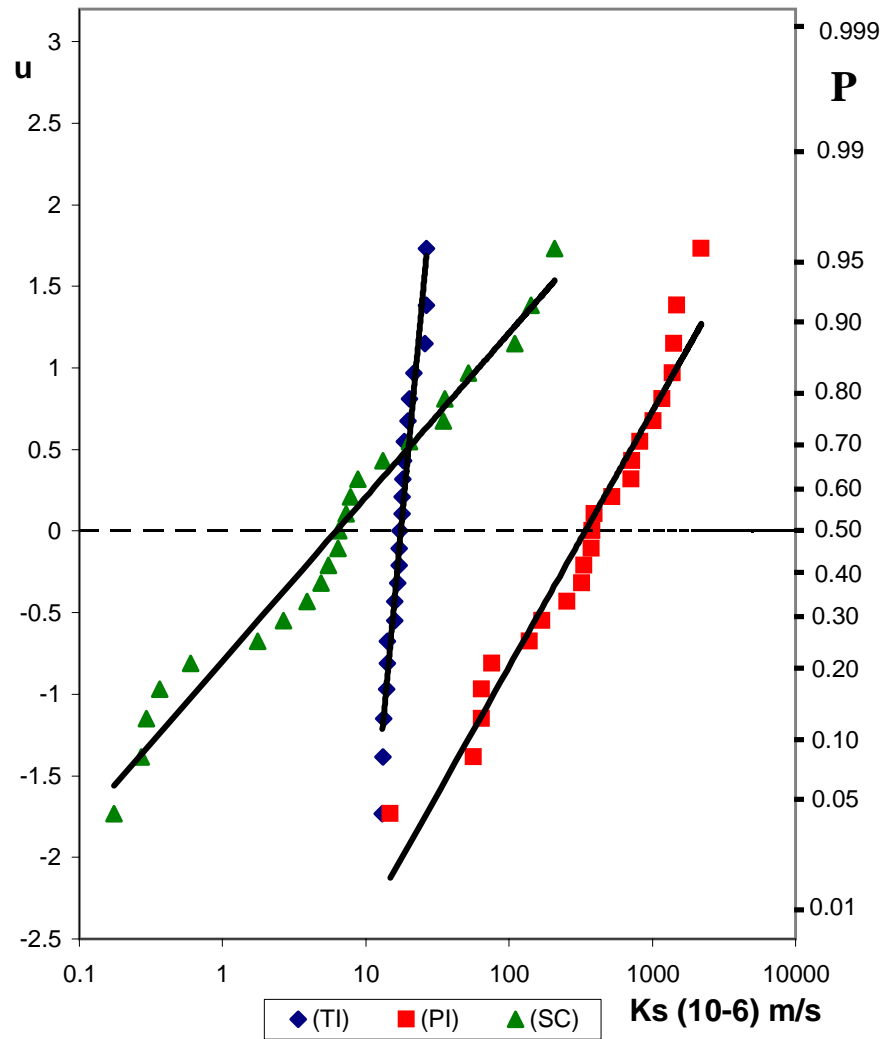

Fig. 2. Fractil diagram of the $k_{s}$ values by the log-normal distribution, for the (TI), (PI) and (SC) measurement methods.

\section{HESSD}

3, 987-1019, 2006

Measurement methods of saturated hydraulic condutivity
C. Fallico et al.

Title Page

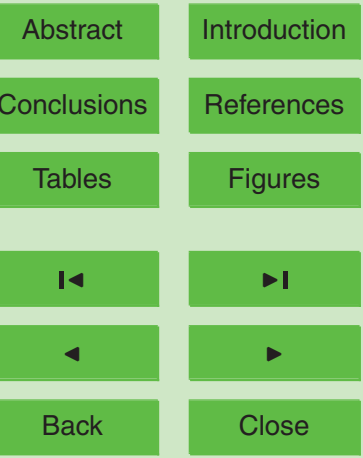

Full Screen / Esc

Printer-friendly Version

Interactive Discussion 


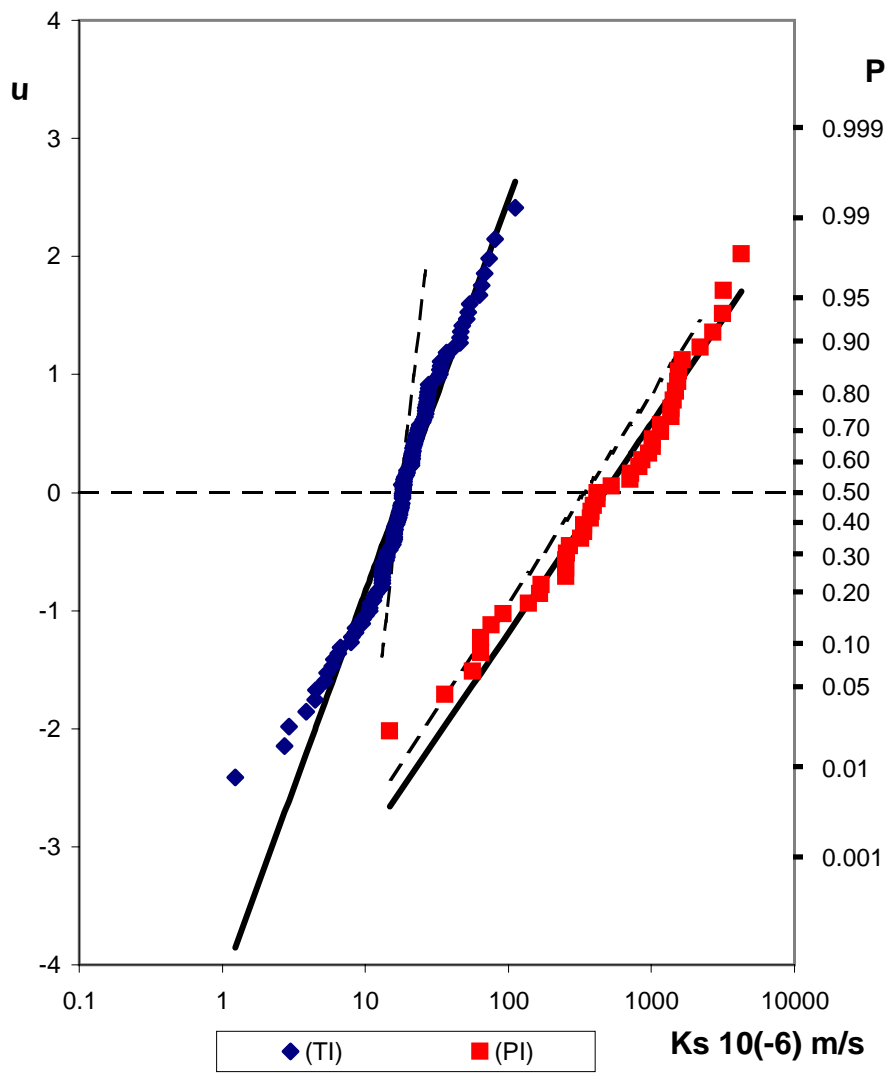

Fig. 3. Fractil diagram of the $k_{s}$ values by the log-normal distribution, for two wide data sets relative to the ( $\mathrm{Tl})$ (126 data) and $(\mathrm{PI})$ (45 data) methods and comparison between the correspondent distributions relative to reduced sets of 23 data.

\section{HESSD}

3, 987-1019, 2006

\section{Measurement methods of saturated hydraulic condutivity}

C. Fallico et al.

\section{Title Page}

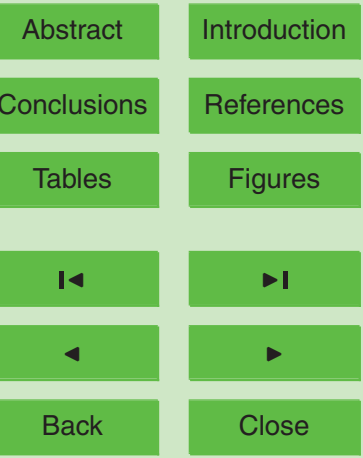

Full Screen / Esc

Printer-friendly Version

Interactive Discussion 